\title{
IgG4-related thyroid disease
}

INSERM

\section{Source}

INSERM. (1999). Orphanet: an online rare disease and orphan drug data base. Ig G4related thyroid disease. ORPHA:64744

Riedel thyroiditis is a fibroinflammatory disorder of the thyroid gland, occuring more frequently in females, characterized a large, hard thyroid mass, and presenting with pressure symptoms (breathing difficul-ties and dysphagia) or voice hoarseness and aphonia (imping ement of recurrent laryngeal nerve). It can often be associated with extracervical fibroinflammatory disorders such as retroperitoneal fibrosis, primary scleroisng cholangitis and autoimmune diseases such as Hashimoto struma, Addison disease, and Biermer disease (see these terms). 